\title{
Preliminary study on biology and feeding capacity of Chelisoches morio (Fabricius) (Dermaptera:Chelisochidae) on Tirathaba rufivena (Walker)
}

\author{
Baozhu Zhong®, Chaojun Lv ${ }^{*+}$ and Weiquan Qin ${ }^{* \dagger}$
}

\begin{abstract}
Background: Chelisoches morio (Fabricius) (Dermaptera:Chelisochidae) is an important predator of Tirathaba rufivena (Walker) (Lepidoptera:Pyralidae). For better use of the natural enemy, a biological study on C. morio was conducted, particularly its developmental duration, survival, fecundity and sex ratio. And the feeding capacity of $C$. morio against T. rufivena was also studied under laboratory conditions.

Results: The biological study on C. morio was revealed that female adults usually lay eggs in egg masses. The number of eggs per female averaged 140.17 eggs, and the incubation period was 7.50 days. The duration of nymphal development included four instars. The immature period was 83.95 days. The longevity of males and females was 58.60 and 93.55 days, respectively. The results from the study on the feeding capacity of $C$. morio using $T$. rufivena as food revealed that C. morio adults could consume 11.08, 7.87, 7.09, 6.82 and 5.89 first-to-fifth-instar T. rufivena larvae, respectively.
\end{abstract}

Conclusions: C. morio showed a huge amount of predation on this pest at all larval stages, implying a significant potential for the use of C. morio in controlling T. rufivena.

Keywords: Chelisoches morio, Biology, Predator, Tirathaba rufivena, Feeding capacity

\section{Background}

Tirathaba rufivena is a moth of the Pyralidae family. It is a major pest insect of palm plants such as Areca catechu L. (betel), Cocos nucifera L. (coconut), and Elaeis guineensis Jacq. It is found from Southeast Asia to the Pacific Islands, including China, Malaysia, the Cook Islands, the Philippines and the tropical region of Queensland. In Hainan, China, damage to palm plants by $T$. rufivena has been severe and widespread. This pest has significantly affected the production of palm plants; the damage rate was found to be $10-67 \%$ in betel plants (A. catechu L.) and 10-40\% in betel blooms, fruit, and

\footnotetext{
*Correspondence: Icj5783@126.com; qwq268@126.com ${ }^{\dagger}$ Chaojun Lv and Weiquan Qin contributed equally to this work Hainan Key Laboratory of Tropical Oil Crop Biology/Coconut Research Institute, Chinese Academy of Tropical Agricultural Sciences, Wenchang 571339, Hainan, People's Republic of China
}

fringe (Fan et al. 1986, 1991). Presently, the control of $T$. rufivena is still focused on chemical pesticides, and this could lead to many problems, for example, resistance to traditional insecticides, environmental pollution, human health impacts, and injury to beneficial species.

Biological control is often considered to be one of the most efficient technique in integrated pest management, and the parasitoid Elasmus punctulatus Verma Hayat was found by Gan et al. (2010, 2011) have a controlling effect on this pest, with a parasitism rate of $20-30 \%$ in the field. The biology and mass rearing of this parasitoid in an insectary was then studied. However, parasitic wasps are vulnerable to climate and require a long time for effective control to occur, leading to instability in their controlling effect. Predators, such as Formica spp., Sitticus spp., Lycosa spp., Forcipula spp., Coccinellidae, and others, are another kind of natural enemy in the control 
of pests, which has been demonstrated by previous studies (Hollingsworth et al. 1988; Zeng et al. 2004; Luo et al. 2005; Wu et al. 2006; Zou et al. 2008; Zhang et al. 2009). The black earwig, Chelisoches morio (Fabricius) is an important predator of many insect pests. Li et al. (2011) reported that $C$. morio adults can preys upon different stages of Brontispa longissima (Coleoptera:Hispidae), and has been used in field for preventing the coconut leaf beetle $B$. longissima in Thailand and Philippins (Chomphukhieo et al. 2008). Abraham and Kurian (1974) showed that C. morio predates eggs and young larvae of red palm weevil Rhynchophorus ferrugineus (Oliv.) (Curculionidae:Coleoptera). Zhong et al. (2016) indicated that $C$. morio is one of the predominant predators showing the potential to control T. rufivena. However, few studies have presented results regarding its biology and feeding capacity on T. rufivena.

This study investigates the biology of C. morio, particularly its developmental duration, survival, fecundity and sex ratio. The feeding capacity of $C$. morio against $T$. rufivena was also studied under laboratory conditions.

\section{Results}

\section{Morphological characteristics}

The abdomens of $C$. morio male and female adults connect when mating, and the mating time varies from 2 to $40 \mathrm{~min}$. Females can perform multiple matings. Female adults begin to lay eggs 4-6 days after mating, and the eggs are generally deposited in masses of 35.7 individuals, on average. In total, the females lay an average of 140.17 eggs each. The adults often flip the eggs after spawning; if outside interference is encountered, the eggs will be transferred to a new hidden area. Newly spawned eggs are creamy white and then turn white and clear when they are near hatching, after 7-8 days. The average width and length are 0.75 and $1.03 \mathrm{~mm}$, respectively. The nymphs have 4 instars, and the newly hatched nymphs are milky white with limited activity and need to be fed by adults. The nymphs can selffeed after a molt. The second- and third-instar larvae are similar, differing only in body length.

The adult body is shiny black or dark brown and has a long and narrow shape with forceps. The forceps of the male adult are longer, and the edge exhibits multiple serrations, which was not obviously seen in females.

\section{The developmental duration of the immature stages}

The developmental duration for the eggs of C. morio was 7.50 days, and that of first- to fourth-instar nymphs was $12.75,10.63,14.53$ and 21.89 days, respectively, under the conditions of rearing with areca core leaves at a constant temperature $\left(26 \pm 1{ }^{\circ} \mathrm{C}\right)$ and a relative humidity $(\mathrm{RH})$ of $65 \pm 5 \%$. Subsequently, the total developmental period (from egg to adult emergence) was 83.95 days (Table 1 ).
Table 1 Duration period and survivor of various developmental stages of $C$. morio Fabricius under laboratory condition $\left(26 \pm 1^{\circ} \mathrm{C}\right.$ and $\left.65 \pm 5 \% \mathrm{RH}\right)$

\begin{tabular}{lllll}
\hline $\begin{array}{l}\text { Stage of devel- } \\
\text { opment }\end{array}$ & $\mathbf{N}$ & $\begin{array}{l}\text { Mean } \pm \text { SE } \\
\text { (days) }\end{array}$ & Range (days) & $\begin{array}{l}\text { Survival rate } \\
\text { (\%) }\end{array}$ \\
\hline Egg & 20 & $7.50 \pm 0.11$ & $7-8$ & 100 \\
Nymph & & $12.75 \pm 0.10$ & $12-13$ & 100 \\
Instar I & 20 & $10-12$ & 99 \\
Instar II & 19 & $10.63 \pm 0.16$ & 10 & 99 \\
Instar III & 19 & $14.53 \pm 0.14$ & $13-15$ & 99 \\
Instar IV & 19 & $21.89 \pm 0.20$ & $20-23$ & 99 \\
Immature & 19 & $83.95 \pm 0.97$ & $78-90$ & \\
\hline
\end{tabular}

a Immature refers to the developmental duration of $C$. morio from egg to adult emergence

The longevity of C. morio adults was observed under laboratory conditions. The life span of adult male and females supplemented with honey water for nutrition was an average of $58.60 \pm 0.52$ and $93.55 \pm 1.25$ days, respectively. The fecundity of female $C$. morio was $140.17 \pm 0.44$ on average.

\section{Feeding capacity of $C$. morio against $T$. rufivena larvae}

The daily predation of first-to-fifth-instar larvae of $T$. rufivena by C. morio was $11.08,7.87,7.09,6.82$ and 5.89, respectively. The maximum feeding capacity of $C$. morio was observed for first-instar larvae of T. rufivena, and the minimum predation was observed against fifth-instar larvae. The results showed that the consumption of prey by C. morio adults decreased as the age of the prey increased (Table 2).

\section{Discussion}

Biology is the basis of the study of insects. Understanding the life history of insects is the basis of mass rearing insect natural enemies in an insectary. The biology of the black earwig, C. morio, was reported overseas many years ago, but there are some differences compared to the

Table 2 Feeding capacity of C. morio (Fabricius) against $T$. rufivena under laboratory condition $\left(26 \pm 1{ }^{\circ} \mathrm{C}\right.$ and $65 \pm 5 \% \mathrm{RH})$

\begin{tabular}{lccc}
\hline $\begin{array}{l}\text { Stage of nymph } \\
\text { development }\end{array}$ & Replicates & Mean \pm SE (days) & Range (days) \\
\hline Instar I & 15 & $11.08^{\mathrm{a}} \pm 0.15 \mathrm{a}$ & $9-13$ \\
Instar II & 15 & $7.87 \pm 0.09 \mathrm{~b}$ & $7-9$ \\
Instar III & 15 & $7.09 \pm 0.12 \mathrm{c}$ & $6-9$ \\
Instar IV & 15 & $6.82 \pm 0.72 \mathrm{C}$ & $5-8$ \\
Instar V & 15 & $5.89 \pm 0.71 \mathrm{~d}$ & $5-7$
\end{tabular}

${ }^{a}$ Means bearing the same letters are not significantly different (LSD; $P<0.05$ ) between treatments 
results of this study, which may be a result of differences in the geographical environment, climate, indoor rearing conditions and the influences of different foods. Using $B$. longissima (Coleoptera:Hispidae) as food, Chomphukhieo et al. (2008) reported that the longevity of male and female adults was $51.40 \pm 0.89$ and $76.75 \pm 1.28$ days, respectively, while females and males can live 93.55 and 58.60 days, respectively, when provided with honey water as supplementary nutrition. Abraham and Kurian (1974) indicated that females feeding with red palm weevil eggs and young larvae lay an average of 156 eggs each, while 140.17 eggs were observed in our study.

The newly hatched nymphs were raised by $C$. morio adults, indicating that the small nymphs will have difficulty surviving without adult parenting, which in accordance with the research of Lv et al. (2012). In addition, we also observed that eggs cannot hatch if the eggs and adults are separated. Wang (1979) and Lv et al. (2012) showed that, in the hatching process, female earwig adults not only keep the eggs at a certain temperature but also that female adults often use their mouthparts to flip the eggs to facilitate egg heating and effective incubation. The understanding of these special habits of C. morio may provide help and reference for large-scale indoor breeding efforts.

The black earwig, C. morio, not only preys upon different stages of B. longissima (Chomphukhieo et al. 2008; Li et al. 2011; Lv et al. 2012) but also predates red palm weevil eggs and young larvae (Abraham and Kurian 1974). Our study indicated that C. morio adults were able to predate $T$. rufivena larvae, especially younger and smaller larvae (11.08), but that they had poorer ability to feed on the old larvae, based on the number predated (5.89). This difference may be related to the insect body nutrient content and the fact that larvae spin silken webs; the nutrition provided by small larvae is limited, while the nutrient content of larger larvae is high but they engage in more spinning, which could restrict black earwig activity and affect their search for prey.

The black earwig, C. morio, is a natural enemy with high activity, and the author survey found that the black earwig prefers a dark and humid habitat. C. morio has potential predator characteristics, as it is often hidden in the axils of leaves or flowers near pests feeding on the leaves and flowers of palm plants, and this species can be used as a supplementary measure together with parasitic wasps in the prevention and control of T. rufivena.

\section{Conclusions}

In summary, C. morio (Dermaptera:Chelisochidae) is an important predator of T. rufivena Walker, and the biological characteristics of this predator were investigated in this study. C. morio showed a huge amount of predation on this pest at all larval stages, implying a significant potential for the use of C. morio in controlling $T$. rufivena.

\section{Methods \\ Predator and prey}

A laboratory population of T. rufivena was established by collecting larvae from infested betel field. The larvae were reared with areca core leaves at a constant temperature $\left(26 \pm 1{ }^{\circ} \mathrm{C}\right), 65 \pm 5 \% \mathrm{RH}$ and a photoperiod of 0:24 L:D in the laboratory, Department of Plant Protection, Coconut Research Institute, Chinese Academy of Tropical Agricultural Sciences, Wenchang, Hainan Province. Individuals of $C$. morio were also collected from the betel field and maintained on $T$. rufivena larvae for more than ten generations under the same laboratory conditions before they were used in this study. Adults of $C$. morio were supplemented with honey water for nutrition.

\section{Observation of biological characteristics of C. morio}

This study was conducted under laboratory conditions at a temperature of $26 \pm 1{ }^{\circ} \mathrm{C}, 65 \pm 5 \% \mathrm{RH}$ and a photoperiod of 0:24 L:D. Second-instar larvae of T. rufivena were placed into a clean transparent glass tube $(20 \mathrm{~mm} \times 200 \mathrm{~mm}$ ), and a pair of newly emerged (one female and one male) C. morio adults was then introduced. Areca core leaves were placed in the glass tube for T. rufivena feeding, and the tube was covered with gauze. Additional larvae were added as they were eaten by $C$. morio. Biological characteristics were studied by daily observation of $C$. morio, including adult mating and spawning behavior and the habits of various developmental stages. This study was repeated 20 times.

\section{Feeding capacity of $C$. morio against $T$. rufivena larvae}

Healthy first-, second-, third-, fourth-, and fifth-instar T. rufivena larvae were placed into clean transparent plastic boxes $(10 \mathrm{~cm} \times 5 \mathrm{~cm} \times 5 \mathrm{~cm})$ with areca core leaves. Each box contained 15 larvae, and 1 female adult black earwig that had been starved for $24 \mathrm{~h}$ was introduced. The number of predated larvae was assessed and recorded daily. Continuous observation occurred for 3 days, and larvae were added according to the number predated. This experiment was repeated 15 times.

\section{Data analysis}

The data were analyzed by SPSS 13.0 software, and the results were expressed as the mean \pm standard error $($ mean $\pm \mathrm{SE})$.

\section{Abbreviations}

C. morio: Chelisoches morio; T. rufivena: Tirathaba rufivena; B. Iongissima: Brontispa longissima; $\mathrm{RH}$ : a relative humidity. 


\section{Authors' contributions}

$\mathrm{BZ}$ and $\mathrm{CL}$ conceived this study. All authors designed and evaluated the experiments. BZ mainly and CL partly performed the experiments. BZ wrote the manuscript. CL and WQ reviewed the article and approved the finalised version. All authors read and approved the final manuscript.

\section{Acknowledgements}

The researchers gratefully acknowledge grants from Key Research and Development Project of Hainan Province, P.R. China (Grant No. ZDYF2016059), Major Planned Science and Technology Project of Hainan Province, P.R. China (Grant No. ZDXM 20120029) and Major Science and Technology Project of Hainan Province, P.R. China (Grant No. ZDZX 2013008-2).

\section{Competing interests}

The authors declare that they have no competing interests.

\section{Consent to publish}

As this manuscript does not contain any individual person's data, the consent to publish is not applicable.

Received: 13 July 2016 Accepted: 1 November 2016

Published online: 09 November 2016

\section{References}

Abraham VA, Kurian C (1974) Chelisoches morio F. (Forficulidae: Dermaptera), a predator on eggs and early instar grubs of the red palm weevil Rhynchophorus ferrugineus F. (Curculionidae:Coleoptera). J Plant Crops 1:147-152

Chomphukhieo N, Suksen K, Uraichuen S, Suasa-ard W (2008) Biology and feeding capacity of Chelisoches morio (Fabricius) (Dermaptera:Chelisochidae) against Brontispa longissima Gestro. In: Proceedings of the 46th Kasetsart University annual conference, Kasetsart, pp 149-154

Fan Y, Gan BC, Chen SL, Du CG, Yang CQ, Cui WT (1986) The investigation and research on Tirathaba rufivena Walk of betel nut. Tradit Chin Med Bull $11: 8-9$
Fan Y, Gan BC, Chen SL, Du CG, Yang CQ (1991) The biological characteristics and control of Tirathaba rufivena. Entomol Knowl 28(3):146-148

Gan BC, Huang LM, Chen XY, Yang XQ, Liu LF (2010) Study on biological characteristics of Elasmus sp. a parasitoid of Tirathaba rufivena Walker. Chin Agric Sci Bull 26(5):219-222

Gan BC, Zhou YK, Yang XQ, He MJ, Huang LM, Liu LF (2011) Mass rearing of Elasmus punctulatus, a parasitoid of Tirathaba rufivena. For Pest Dis 30(4):29-30

Hollingsworth R, Meleisea S, losefa T (1988) Natural enemies of Brontispa longissima (Gestro) in Western Samoa. Alafua Agric Bull 13(1):41-45

Li CX, Huang SC, Ma ZL, Qin WQ, Yu FY, Zhang ZH (2011) Predatory functional response of black earwig Chelisoches morio to coconut leaf beetle Brontispa longissima. J Fruit Sci 28(2):353-357

Luo J, Cai ZJ, Xie E (2005) Primary investigations of natural enemy resources in loquat orchard. Entomol J East China 14(4):358-361

Lv BQ, Zhu WJ, Jin QA, Wen HB, Peng ZQ, Du YZ (2012) Biology of Chelisoches morio as an enemy of Brontispa longissima. Chin J Appl Entomol 49(5):1268-1273

Wang LY (1979) A study on large earwigs habits parenting habits. Entomol Knowl 16(5):211-215

Wu Q, Liang GW, Zeng L, Lu YY (2006) Host plants and natural enemies for coconut leaf beetle, Brontispa longissima (Gestro) in Shenzhen. Chin Bull Entomol 43(4):530-534

Zeng L, Zhang ZH, Lu YY, Zhang WQ (2004) Response function of the Earwig Chaetospania sp. On the banana moth Opogona sacchari (Bojer). J Huazhong Agric 23(2):218-221

Zhang ZR, Liang LH, Huang WJ, Wang JH, Huang HJ (2009) Investigation of occurrence of weaver ant Oecophylla smaragdina in cashew plantations of Hainan Province. Environ Entomol 31(1):68-72

Zhong BZ, Lv CJ, Qi XM, Qin WQ, Hong XJ (2016) Investigation of damage and natural enemies of Tirathaba rufivena on Areca catechu in Hainan Province. For Pest Dis 35(4):21-24

Zou GC, Lu JQ, Wei YM (2008) Predatory functional response of Forcipula sp. against Eoeurysa flavaplitafa Muir. modern agricultural. Sci Technol 14(120):122

\section{Submit your manuscript to a SpringerOpen ${ }^{\odot}$ journal and benefit from:}

- Convenient online submission

- Rigorous peer review

- Immediate publication on acceptance

- Open access: articles freely available online

- High visibility within the field

- Retaining the copyright to your article

Submit your next manuscript at springeropen.com 